\title{
Biologia e Química em obras de arte: um estudo do estado da arte, da percepção sobre o conhecimento discente e das aplicações do tema
}

\author{
Biology and Chemistry in works of art: a study of the state of art, perception on discent knowledge \\ and the theme
}

Biología y Química en las obras de arte: un estudio del estado del arte, la percepción sobre el conocimiento discente y las aplicaciones temáticas

Recebido: 28/10/2021 | Revisado: 07/11/2021 | Aceito: 14/11/2021 | Publicado: 24/11/2021

\author{
Érica de Melo Azevedo \\ ORCID: https://orcid.org/0000-0001-8001-7731 \\ Instituto Federal do Rio de Janeiro, Brasil \\ E-mail: erica.azzevedo@ifrj.edu.br \\ Thamires da Conceição Silva \\ ORCID: https://orcid.org/0000-0002-2223-5930 \\ Universidade Federal do Rio de Janeiro, Brasil \\ E-mail: thamiresdac.silva@gmail.com
}

\begin{abstract}
Resumo
A proposta do presente trabalho foi realizar uma pesquisa bibliográfica para identificar as técnicas de produção, análise e matérias primas utilizadas em preparo de tintas e pigmentos em pinturas. Essas informações foram utilizadas para a aplicação de uma avaliação diagnóstica com o objetivo de desenvolver, futuramente, atividades interdisciplinares com as disciplinas de química, biologia e Arte. As etapas desse trabalho foram a realização de uma pesquisa sobre o estado da arte nos períodos de 2000-2020 utilizando as plataformas Science Direct e Google Acadêmico e uma avaliação diagnóstica sobre a utilização da química e biologia na arte a partir da aplicação de um questionário do Google Forms para alunos de duas instituições de ensino. Os resultados obtidos no Science Direct mostraram que ocorreu um aumento de $72 \%$ na publicação de trabalhos a respeito de pigmentos naturais e que trabalhos relacionados à pintura a têmpera tiveram um decréscimo de 39,5\%. Em relação a pigmentos de plantas em obras de arte, ocorreu um aumento de 45,9\%. Apesar disso, os resultados obtidos pelo Google Acadêmico mostraram que ocorreu um aumento de pesquisas a respeito de pigmentos naturais $(15 \%)$ e pintura a têmpera $(8,7 \%)$. Alunos de faixa etária 18-28 anos e os que possuem ensino técnico demonstraram desenvolver melhor suas respostas, enquanto que a faixa etária 51-61 anos demonstrou possuir maior dificuldade em elaborar suas respostas. Observou-se também que os alunos, em geral, responderam de forma mais adequada as perguntas que tinham maior relação com sua área de formação.
\end{abstract}

Palavras-chave: Interdisciplinaridade; Avaliação diagnóstica; Pigmentos naturais; Pintura a têmpera.

\begin{abstract}
The purpose of this work was to perform a bibliographical search to identify the techniques of production, analysis and materials used in the preparation of paints and pigments in paintings. This information was used for the application of a diagnostic evaluation with the objective of developing, in the future, interdisciplinary activities with the disciplines of chemistry, biology and art. The steps of this work were to carry out a research on the state of the art in the periods 2000-2020 using the Science Direct and Google Scholar platforms and a diagnostic evaluation of the use of chemistry and biology in art based on the application of a questionnaire from the Google forms for students from two educational institutions. The results obtained in Science Direct indistinctly that there is an increase of $72 \%$ in the publication of works about natural pigments and that works related to tempera painting had a decrease of $39.5 \%$. In relation to plant pigments in works of art, there was an increase of $45.9 \%$. Despite this, the results obtained by Google Scholar sensitive that there is an increase in searches regarding natural pigments $(15 \%)$ and tempera paint (8.7\%). Students aged 18-28 years and those with technical education demonstrated to develop their best answers, while those aged 51-61 years have greater difficulty in preparing their answers. It was also observed that students, in general, responded more adequately to questions that were more related to their area of training.
\end{abstract}

Keywords: Interdisciplinarity; Diagnostic evaluation; Natural pigments; Tempera painting.

\section{Resumen}

El propósito de este trabajo fue realizar una búsqueda bibliográfica para identificar las técnicas de producción, análisis y materias primas utilizadas en la preparación de pinturas y pigmentos en pinturas. Esta información se utilizó para la 
aplicación de una evaluación diagnóstica con el objetivo de desarrollar, en el futuro, actividades interdisciplinarias con las disciplinas de la química, la biología y el arte. Los pasos de este trabajo fueron la realización de una evaluación diagnóstica sobre el estado del arte en los períodos 2000-2020 utilizando las plataformas Science Direct y Google Académico y una evaluación diagnóstica del uso de la química y la biología en el arte mediante la aplicación de un cuestionario de Google forms para estudiantes de dos instituciones educativas. Los resultados obtenidos en Science Direct mostraron que hubo un aumento del $72 \%$ en la publicación de trabajos sobre pigmentos naturales y que los trabajos relacionados con la pintura al temple tuvieron una disminución del 39,5\%. En relación a los pigmentos vegetales en las obras de arte, hubo un aumento del 45,9\%. A pesar de esto, los resultados obtenidos por Google Académico mostraron que hubo un aumento en las búsquedas de pigmentos naturales (15\%) y pintura con témpera $(8,7 \%)$. Los estudiantes de 18 a 28 años y aquellos con educación técnica mostraron desarrollar mejor sus respuestas, mientras que el grupo de edad de 51 a 61 años mostró mayor dificultad para preparar sus respuestas. También se observó que los estudiantes, en general, contestaron de manera más adecuada a las preguntas que estaban más relacionadas con su área de formación.

Palabras clave: Interdisciplinariedad; Evaluación diagnóstica; Pigmentos naturales; Pintura com témpera.

\section{Introdução}

Os pigmentos são substâncias coloridas e importantes constituintes da tinta. Estes podem ser retirados diretamente da natureza ou obtidos através de reações químicas. Os primeiros são chamados de pigmentos naturais e os últimos, artificiais ou sintéticos (Gomes, Rosina, Oosterbeek, 2014; Volpe \& Marques, 2016). Segundo Cruz (2006a), maior parte dos pigmentos existentes são de origem mineral, e outros diversos pigmentos inorgânicos podem ser obtidos a partir destes.

Com o desenvolvimento da indústria química, a partir do final do século XIX, os pigmentos naturais foram trocados pelos artificiais devido à possibilidade de produção em larga escala e facilidade de acesso a esses produtos. Segundo Alves (2006), um dos primeiros pigmentos sintéticos a ser comercializado foi o azul de metileno, que tinha aplicabilidade no tingimento de seda e lã. No entanto, atualmente, em muitos setores industriais têm crescido o interesse por pigmentos naturais (Dufossé et al., 2005; Almeida et al, 2007; Mello \& Suarez, 2012; Cruz, 2007b).

A avaliação deve ser considerada um processo de acompanhamento da aprendizagem e pode ser nortear o planejamento de metodologias de ensino, tornando sua realização, no início do curso, já que é essencial para saber os conhecimentos prévios dos discentes em relação ao conteúdo (Mendonça, 2013).

As avaliações de aprendizagem podem ser classificadas em somativas, formativas e diagnósticas. A avaliação diagnóstica possui como objetivo mensurar a competência ou o grau de conhecimento que os alunos possuem a respeito de determinado assunto, e a partir da análise dos resultados, o professor pode elaborar atividades baseando-se no conhecimento que os alunos demonstraram ter. Este tipo de avaliação também é chamado de avaliação inicial, pois informa a capacidade dos alunos antes de serem submetidos a algum processo de ensino-aprendizagem (Kraemer, 2005). Esse tipo de avaliação contribui para elaboração de estratégias de ensino e planejamento de atividades voltadas a uma aprendizagem significativa.

Todo conhecimento mantém um diálogo permanente com outros conhecimentos a partir do questionamento, da complementação, da ampliação de aspectos, entre outros fatores (Parâmetros Curriculares Nacionais, 2000). Para Navegantes et al. (2000), a interdisciplinaridade é uma abertura que permite o diálogo entre os diversos saberes, e esta tentativa de cooperação entre as disciplinas não é recente.

Os desafios enfrentados pelos professores que desejam trabalhar de forma interdisciplinar são muitos. Entre os fatores a serem superados estão a organização e coordenação, comunicação e linguagem escolhida, e pesquisa (Teixeira, 2004). A interdisciplinaridade é uma das propostas dos Parâmetros Curriculares Nacionais (1997) cuja função é reduzir a fragmentação no ensino:

"A interdisciplinaridade questiona a segmentação entre os diferentes campos de conhecimento produzida por uma abordagem que não leva em conta a inter-relação e a influência entre eles — questiona a visão compartimentada (disciplinar) da realidade sobre a qual a escola, tal como é conhecida, historicamente se constituiu. Refere-se, portanto, a uma relação entre 
disciplinas (Parâmetros Curriculares Nacionais, 1997)”.

Neste trabalho foi pretendido realizar um estudo do estado da arte qualitativo sobre técnicas de extração de pigmentos e corantes, técnicas de pintura e um diagnóstico da percepção e conhecimento de discentes da área de química e biologia sobre estes temas. Dessa forma, o objetivo geral deste trabalho foi discutir a importância da interdisciplinaridade no processo de ensino-aprendizageme realizar uma avaliação diagnóstica por meio da aplicação de um questionário do Google Forms. A avaliação diagnóstica tem como objetivo avaliar o conhecimento empírico e científico de estudantes da área de química e biologia sobre alguns conceitos sobre pinturas do ponto de vista de ambas as áreas da ciência e a sua relação com a arte.

Os objetivos secundários foram a realização de pesquisa bibliográfica para buscar técnicas utilizadas na extração de pigmentos e corantes e técnicas de pintura. Essa revisão também serviu de base para a elaboração do formulário diagnóstico.

\section{Metodologia}

\subsection{Primeira etapa}

A primeira etapa consistiu na revisão bibliográfica, a partir da qual foi preparado o formulário a ser disponibilizado para os estudantes. A pesquisa foi realizada pelo Science Direct e Google acadêmico. Foram utilizadas as seguintes palavraschave: pigmentos naturais, pintura a têmpera e pigmentos de plantas em obras de arte. Sendo a busca em língua inglesa na Plataforma Science Direct, e em língua portuguesa no Google Acadêmico.

A pesquisa sobre o estado da arte realizada foi do tipo qualitativa, uma vez que realizou-se uma pesquisa acerca das publicações sobre o tema a partir da avaliação da quantidade de publicações sobre o tema, mas sem detalhar se aprofundar nos conteúdos dos trabalhos encontrados. Essa pesquisa prévia teve como objetivo servir de suporte para a elaboração do formulário diagnóstico que foi aplicado e que será detalhado a seguir.

Segundo Pereira et al (2018), na pesquisa do tipo qualitativa a interpretação do pesquisador é essencial. Nesse tipo de metodologia as opiniões do pesquisador são demonstradas e a coleta de dados muitas vezes é feita por meio de entrevistas com questões abertas. Em relação ao objetivo maior da pesquisa qualitativa, esta foi utilizada como meio para uma pesquisa-ação educacional. Segundo Tripp (2005), esse tipo de pesquisa é uma estratégia para o desenvolvimento de educadores e pesquisadores para aprimorar ensino e aprendizado. Apesar de existirem variedades quanto aos tipos de pesquisa-ação, observa-se um padrão. O ciclo observado, na maioria dos casos, parte de uma avaliação da prática, planeja-se uma melhora da prática e, em seguida, implementa-se uma ação para a melhora desta.

\subsection{Aplicação de formulário eletrônico para pesquisa}

A pesquisa foi realizada no período de 16 de abril de 2020 a 23 de abril de 2020. O conjunto estudado foi composto por alunos do consórcio CEDERJ e Instituto Federal do Rio de Janeiro (IFRJ) campus Rio de Janeiro e Nilópolis, e correspondeu a um total de 56 alunos.

Foi elaborado um questionário que possuía perguntas abertas e fechadas:

1.As pinturas rupestres são representações artísticas muito antigas. De que material você acha que elas eram feitas?

2.Qual é a diferença entre pigmento e corante para você?

3.Dê ao menos um exemplo de corante de origem orgânica.

4.Dê ao menos um exemplo de corante origem inorgânica.

5.Cite pigmentos presentes nas plantas.

6.Dê exemplo de algum material da natureza que pode ser usado para produzir um pigmento.

7.Você acha que a Biologia e a Química podem ser aplicadas na arte? 
( ) $\mathrm{Sim}$

( ) Não

( ) Não sei

7.1 Caso tenha assinalado que "sim", diga de que maneira.

7.2 Caso tenha assinalado que "não", diga de que maneira.

\section{Resultados e Discussão}

\subsection{Pesquisa bibliográfica e Estado da arte}

A respeito da pesquisa realizada na plataforma Science Direct utilizando as palavras-chave: pigmentos naturais, pintura a têmpera e pigmentos de plantas em obras de arte, em inglês. Os resultados obtidos se encontram abaixo na forma de descrições.

- $\quad$ Pigmentos naturais: 5195 trabalhos foram publicados de 2000 até 2010 e 8943 de 2010 até 2020.

- $\quad$ Pintura a têmpera: 124 trabalhos foram publicados de 2000 a 2010 e 75 de 2010 até 2020.

- $\quad$ Pigmentos de plantas em obras de arte: 122 trabalhos foram encontrados de 2000-2010 e 178 de 2010-2020.

A respeito da pesquisa realizada na plataforma Google Acadêmico utilizando as palavras chave: pigmentos naturais, pintura a têmpera e pigmentos de plantas em obras de arte, os resultados obtidos se encontram abaixo:

- $\quad$ Pigmentos naturais: 246.000 trabalhos foram publicados de 2000 até 2010 e 283.000 de 2010 até 2020.

- $\quad$ Pintura a têmpera: 15.000 trabalhos foram publicados de 2000 a 2010, e 16.300 de 2010 até 2020.

- $\quad$ Pigmentos de plantas em obras de arte: 115.000 trabalhos foram encontrados de 2000-2010 e 110.000 de 2010-2020.

A proposta desta avaliação não é detalhar os temas abordados nos trabalhos acadêmicos, mas fazer uma abordagem qualitativa. A busca em duas plataformas diferentes, sendo uma com materiais apenas em língua inglesa e outra com materiais predominantemente na língua portuguesa tem como proposta avaliar a produtividade acadêmica nessas duas línguas e avaliar as diferenças em quantidade de produção acadêmica entre as décadas de 2000-2010 e 2010-2020.

Os principais temas abordados nesses trabalhos eram: técnicas para extração e aplicação de tintas e pigmentos; análise de pinturas utilizando técnicas químicas e físicas. Foram considerados todos os trabalhos contendo as palavras-chave descritas, não sendo classificados conforme o tipo (dissertação, artigo, resumo, etc). Segundo Mugnaini e Strehl (2008) que as citações no Google acadêmico deixaram de funcionar exclusivamente como recurso de recuperação de documentos úteis sobre um dado tema, para ser um indicador de visibilidade das publicações. Santos e Santos (2017) destacam a plataforma em questão como uma alternativa promissora, principalmente acerca da revisão de literatura, que se define como uma etapa relevante em um projeto de pesquisa.

Analisando-se os resultados obtidos na plataforma Science Direct, foi percebido que ocorreu um aumento de estudos sobre pigmentos naturais $(72,0 \%)$ e também sobre pigmentos de plantas encontrados em obras de arte $(45,9 \%)$. Estes consideráveis aumentos nos últimos anos podem ter relação com o fato de que tem crescido, em diversos setores industriais, a preferência por pigmentos naturais. Apesar dos pigmentos artificiais poderem ser produzidos em larga escala, os naturais, geralmente, apresentam baixa toxicidade e os de origem inorgânica, são inertes. Atualmente, muitas indústrias farmacêuticas e de alimentos têm explorado pigmentos de origem vegetal devido as diversas vantagens que possuem, como por exemplo, propriedades antioxidantes e por muitos deles auxiliarem na prevenção de doenças crônicas não transmissíveis.

Foi percebida uma diminuição de pesquisas sobre pintura a têmpera (39,5\%). Pode-se dizer que um dos possíveis motivos para isso se deve ao desenvolvimento de outras técnicas que surgiram com o intuito de resolver alguns problemas apresentados por esse estilo: sensibilidade a umidade, mudança de tonalidade ao secar e tempo rápido de secagem. A pintura a 
óleo foi a técnica que, inicialmente, substituiu a pintura a têmpera, resolvendo principalmente, a impossibilidade de pintar quadros com movimentos, fornecendo ao pintor maior flexibilidade na pintura, por possuir um tempo maior de secagem.

Esta substituição pode ser confirmada com o aumento de pesquisas sobre pintura à óleo. A quantidade de publicações a respeito desse tema nos períodos de 2000 a 2010 foram 755, e entre 2010 a 2020 foram encontrados 897 trabalhos no Science Direct.

Em relação à pesquisa realizada no Google Acadêmico, foi notado um aumento de pesquisas a respeito de pigmentos naturais $(15,0 \%)$ e pintura a têmpera $(8,7 \%)$, e uma diminuição de pesquisas sobre pigmentos de plantas encontrados em obras de arte $(4,3 \%)$. Além disso, também foram encontradas quantidades muito maiores de trabalhos no Google Acadêmico do que no Science Direct.

Estas divergências podem ter ocorrido, pois na primeira plataforma a variedade de fontes é maior: artigos científicos, resumos, monografias, teses, revistas, livros, entre outros. A busca realizada na plataforma Science Direct mostrou resultados de maior qualidade, mais específicos e esperados porque filtra melhor as palavras-chave, e as fontes são poucas quando comparadas ao Google Scholar, sendo: artigos, revistas científicas e livros.

\subsection{Aplicação de formulário eletrônico para pesquisa}

A partir da aplicação do questionário, segue abaixo, em forma de gráficos e descrições, os resultados obtidos. As variáveis analisadas foram: o curso, o nível de formação e a idade dos entrevistados (Figura 1).

Figura 1. Idade dos entrevistados.

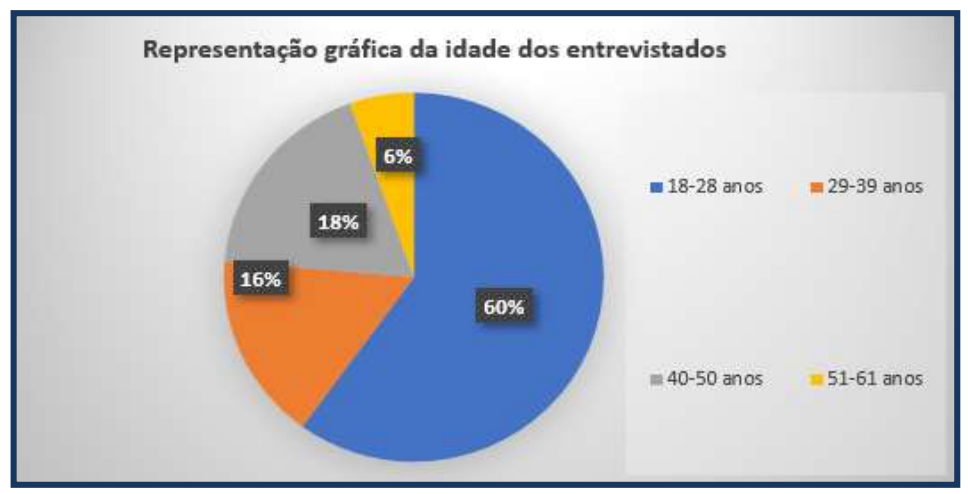

Fonte: Autores.

De acordo com o gráfico acima, $60 \%$ dos entrevistados possuíam entre 18 e 28 anos; $16 \%$ possuíam 29 a 39 anos; 18\%, 40 a 50 anos, e apenas $6 \%$ possuíam 51 a 61 anos. Foi considerado importante conhecer a idade dos entrevistados para saber se a faixa etária poderia influenciar na percepção ou posicionamento a respeito do assunto. O perfil de estudantes é bastante diversificado, e isto é um reflexo da expansão e do acesso ao ensino, especialmente dos cursos EAD e semipresenciais. De acordo com o CENSO da Associação Brasileira de Educação a Distância 2018-2019 (ABED) 49,2\% dos estudantes de cursos semipresenciais tem idade entre 21 e 30 anos e $0,9 \%$ têm mais de 41 anos. Em relação aos cursos presenciais, 48,5\% apresentam idade entre 21 e 30 anos e 2,5\% têm mais de 41 anos. Dessa forma, observa-se que o perfil dos entrevistados é semelhante.

Os entrevistados que possuíam 18-28 anos, pareciam entender melhor sobre maior parte das questões abordadas, apresentando respostas mais elaboradas que as outras faixas etárias. Enquanto que a faixa etária 51-61 anos, demonstrou muita dificuldade em elaborar suas respostas em geral. 
A evidente dificuldade da faixa etária 51-61 anos em elaborar suas respostas pode ser explicada pelo fato de muitos destes entrevistados não terem dado continuidade a seus estudos logo após terminarem a educação básica, o que provavelmente gerou, com o passar do tempo, o esquecimento de diversos conceitos. É importante ressaltar que muitos dos conceitos obtidos na educação básica são fundamentais para o aprendizado de outros durante a graduação. Já em relação aos entrevistados mais novos, o que ocorre é o oposto, a parte deu continuidade aos estudos, ingressando em algum curso superior logo após terminarem a educação básica.

Em relação ao nível e área de formação, para melhor entendimento, os entrevistados foram divididos em dois subgrupos: o primeiro subgrupo consistiu nos entrevistados que eram estudantes de graduação ou que possuíam alguma formação superior (subgrupo 1). O segundo subgrupo, consistiu nos entrevistados que eram estudantes de curso técnico ou que possuíam, apenas, formação técnica (subgrupo 2). É possível observar uma representação da porcentagem dos entrevistados pela área que cursam (Figura 2):

Figura 2. Porcentagem dos entrevistados pela área que cursam.

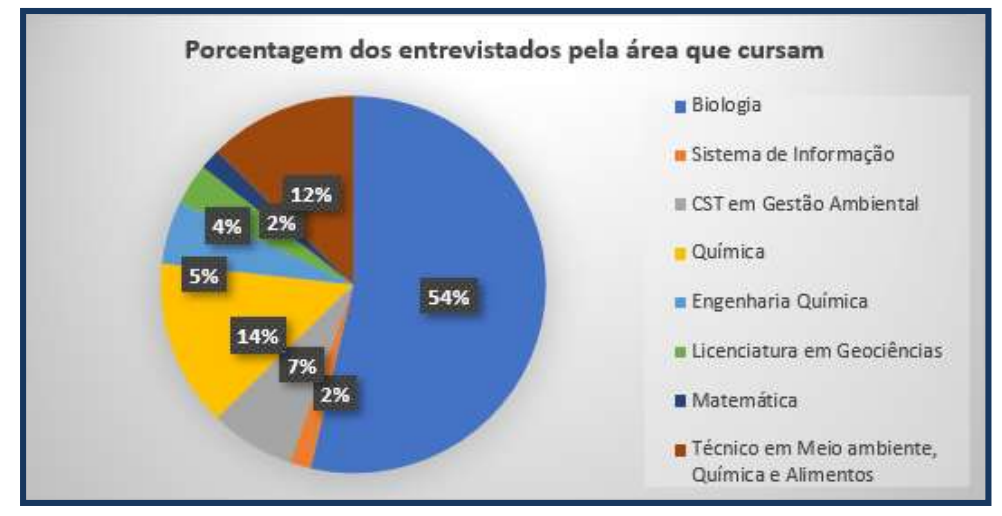

Fonte: Autores.

Foi percebido que 54\% eram estudantes do curso de bacharelado ou licenciatura em Biologia, sendo um estudante já formado na área; $14 \%$ dos entrevistados eram alunos dos cursos de bacharelado ou licenciatura em Química ou Química Industrial; 7\% eram estudantes do Curso Superior de Tecnologia em Gestão Ambiental; 5\% eram estudantes de Engenharia Química; 4\% cursavam licenciatura em Geociências, e apenas 2\% dos entrevistados, eram alunos de Matemática ou Sistema de Informação.

Observou-se que 29\% dos entrevistados possuíam algum tipo de formação técnica; $63 \%$ eram estudantes de algum curso superior; $7 \%$ possuía formação superior, e apenas $1 \%$ possuía outra formação. Neste caso, mestrado. Estas informações podem ser encontradas na Figura 3. 
Figura 3. Nível de formação dos entrevistados.

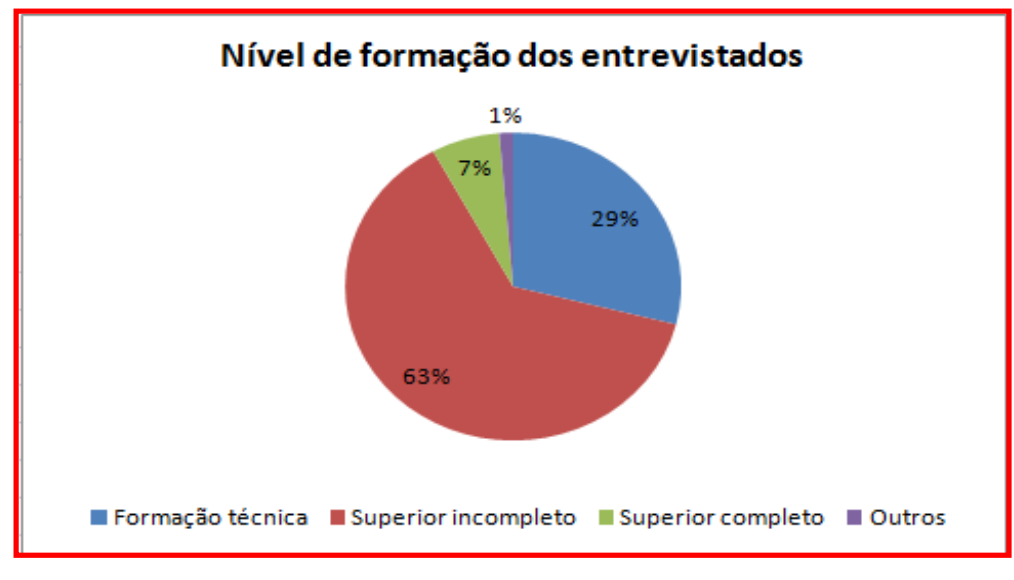

Fonte: Autores.

Entre as formações técnicas observadas, estão as seguintes áreas: Análises Clínicas, Controle Ambiental, Enfermagem, Química, Segurança do Trabalho e Vigilância sanitária. Sendo indivíduos formados em Controle Ambiental ou Química, maior parte dos entrevistados. Em relação aos entrevistados que possuíam só formação técnica, (subgrupo 2), foi percebido que $43 \%$ eram da área de técnico em Controle Ambiental; 43\% da área de técnico em Química, e apenas 14\%, da área de técnico em Alimentos. A Figura 4 mostra as informações mencionadas acima.

Figura 4. Porcentagem dos entrevistados do ensino técnico.

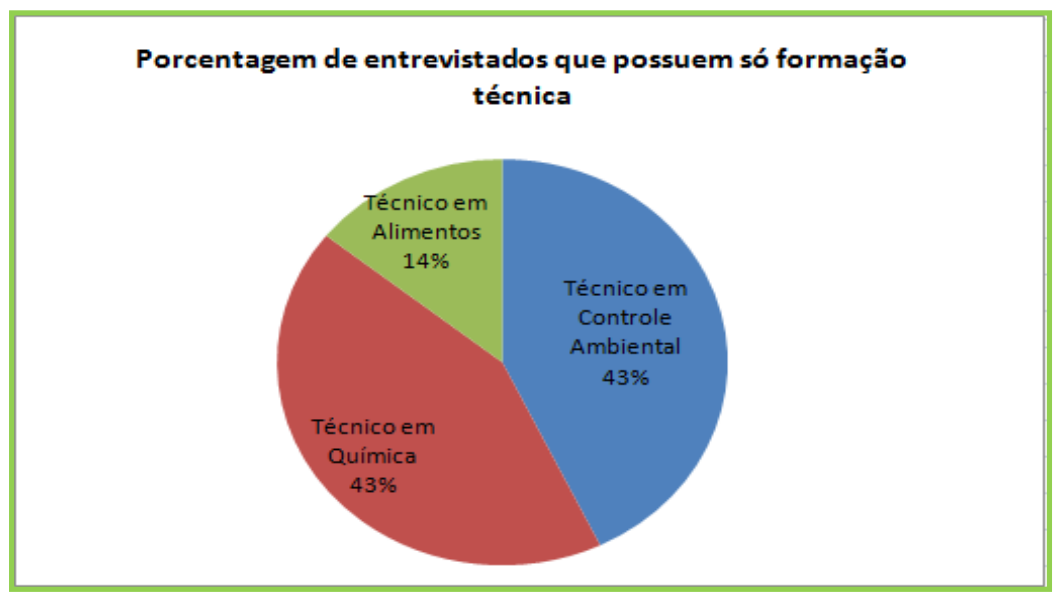

Fonte: Autores.

Dos entrevistados da área de técnico em Controle Ambiental, todos eram formados. Já entre os entrevistados da área de técnico em Química e Alimentos, um entrevistado era estudante do último período. Foi observado que os indivíduos que possuíam formação técnica em Química ou Controle Ambiental desenvolveram de melhor modo as respostas, quando comparados aos outros níveis de formação. Também foi possível verificar de forma qualitativa, o rendimento de todas as faixas etárias em cada uma das perguntas elaboradas no questionário. As Figuras 5, 6, 7 e 8 mostram estas informações. 
Figura 5. Porcentagem das respostas da faixa etária 18-28 anos.

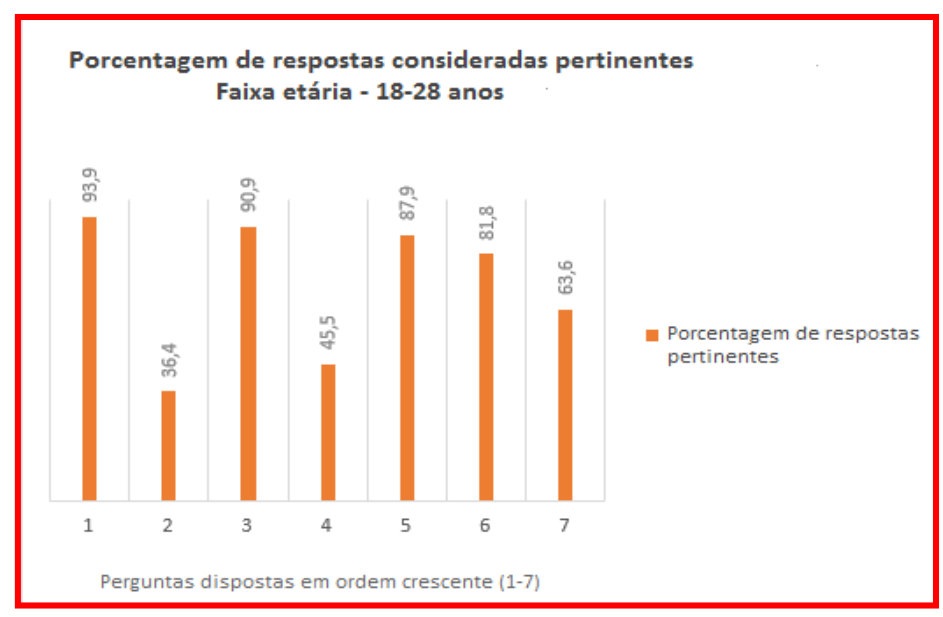

Fonte: Autores.

Na Figura 6 estão apresentadas as respostas consideradas pertinentes pelos autores para a faixa etária de 29-39 anos. Os menores percentuais foram observados para as perguntas 2,4 e 7. A pergunta 2 foi uma das que apresentou menor percentual de acerto, uma vez que se trata de um conceito técnico e específico e por isso muitos estudantes não dominam o assunto.

Figura 6. Porcentagem das respostas da faixa etária 29-39 anos.

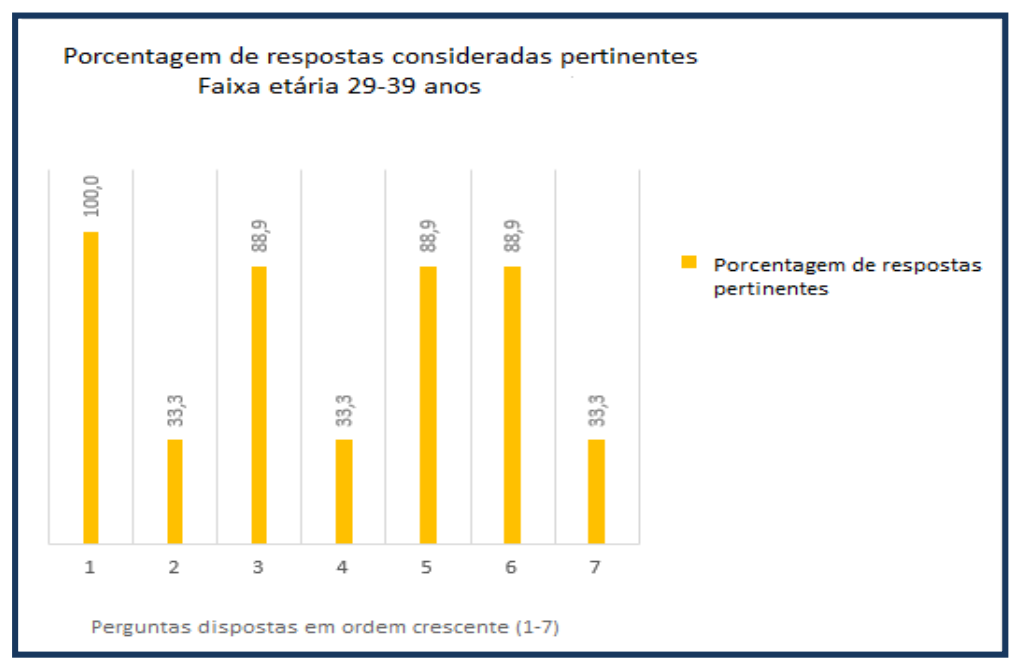

Fonte: Autores.

A faixa etária de 40-50 anos também apresentou um menor percentual de respostas consideradas pertinentes para todas as perguntas. No entanto, foi observado um padrão de acertos em todas as faixa-etárias. 
Figura 7. Porcentagem das respostas da faixa etária 40-50 anos.

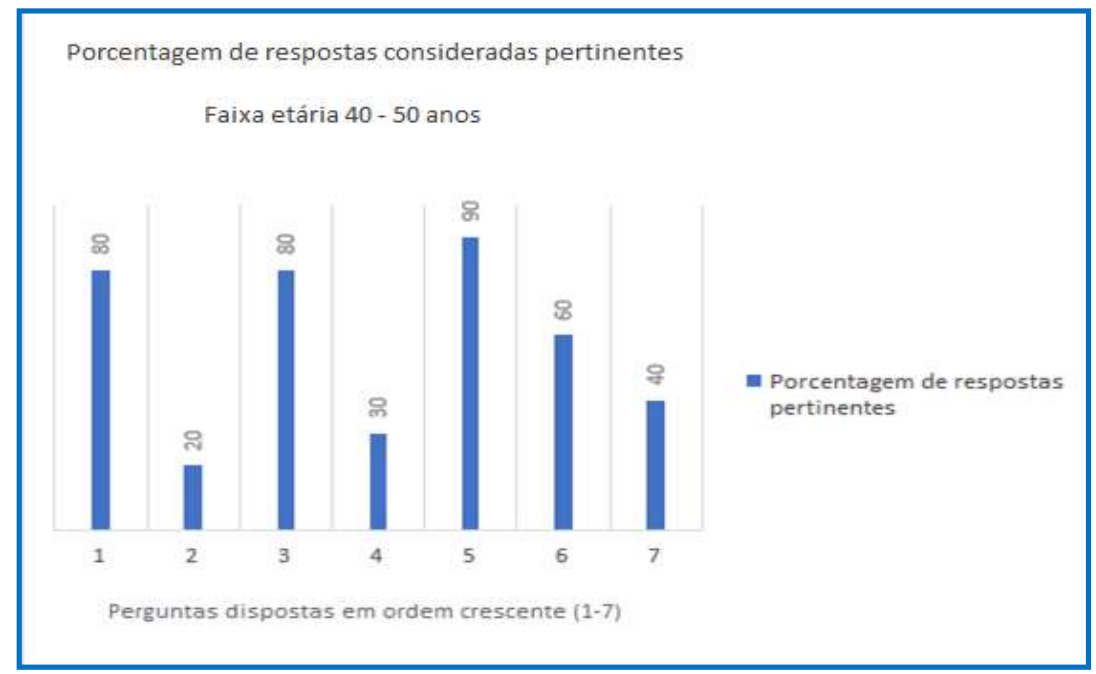

Fonte: Autores.

Figura 8. Porcentagem das respostas da faixa etária 51-61 anos.

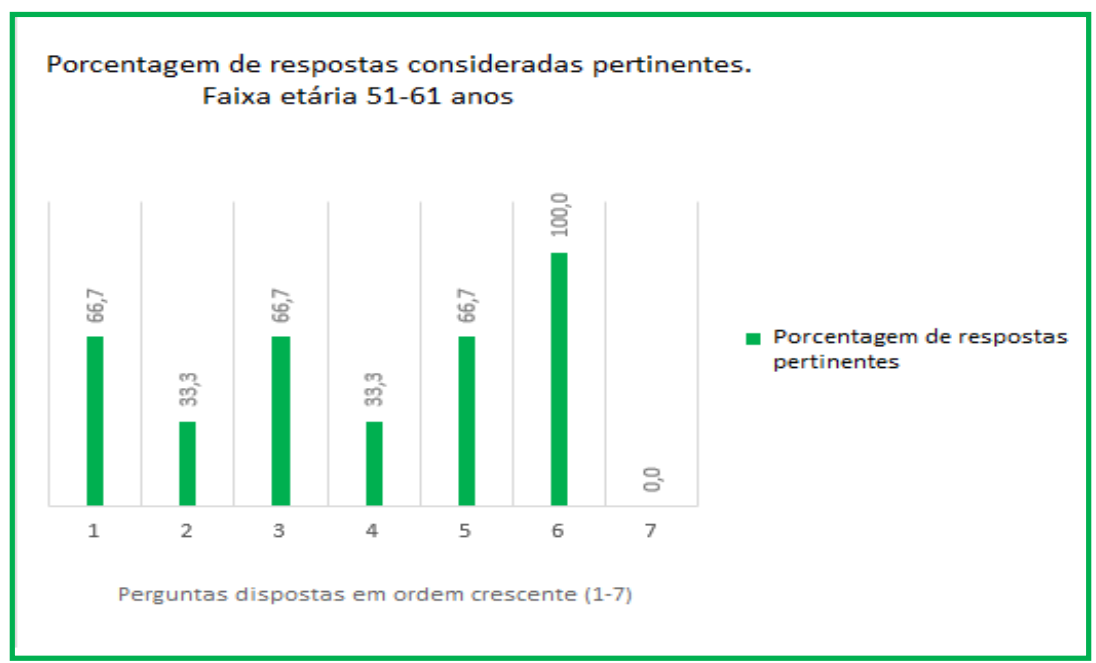

Fonte: Autores.

Os elementos utilizados em pinturas rupestres mais citados foram: urucum, sangue, vegetais e carvão. Os pigmentos de origem orgânica mais citados foram: beterraba, urucum e açafrão. Apesar disso, outras substâncias como alizarina, alaranjado de metila foram mencionadas por alunos do curso técnico ou graduação em Química. A justificativa para essas respostas diferenciadas pode estar relacionada ao uso destas substâncias nas práticas laboratoriais de química. O alaranjado de metila, por exemplo, é utilizado como indicador de $\mathrm{pH}$ nas práticas de titulação. Embora, a clorofila tenha sido o pigmento de plantas mais mencionado pelos entrevistados, foi observado que dois estudantes de licenciatura em Biologia citaram antocianinas, betacaroteno e flavonoides. A justificativa para as respostas diferenciadas desses dois estudantes pode estar relacionada à questão de que as substâncias mencionadas acima, geralmente são estudadas em matérias específicas. As antocianinas, por exemplo, são estudadas na disciplina de Bioquímica I do curso de licenciatura em Biologia (consórcio CEDERJ), na prática de titulação que utiliza o repolho roxo como indicador de $\mathrm{pH}$ (Sivico et al, 2021).

A respeito da extração de pigmentos de materiais da natureza, um número grande de alunos citou plantas, seguidas por urucum e açafrão. No entanto, dois entrevistados mencionaram cochonilhas, um deles, estudante do curso técnico em 
Alimentos. Embora o carmim não seja mais utilizado em obras de arte, é importante dizer que o ácido carmínico, derivado desses insetos, é utilizado por muitas indústrias de alimentos na fabricação de diversos produtos, como por exemplo, os iogurtes, biscoitos e produtos cárneos (Crizel, 2017, p. 12-13). Foi percebido que os entrevistados tiveram dificuldade em responder sobre a diferença entre pigmento e corante. Muitos disseram que o pigmento é natural e o corante, artificial, e alguns que pigmento e corante são sinônimos. Este resultado era esperado pelo fato destas substâncias possuírem a mesma função e apresentarem diferenças pouco perceptíveis, que ainda são discutidas entre os autores.

Estudantes de graduação em Química ou Engenharia Química diferenciaram melhor estas substâncias quanto à solubilidade e poucos foram os de Biologia. Uma justificativa para esta diferença é que a amostragem de alunos da área de Biologia (54,0\%) era maior que a amostragem de alunos de Química (14,0\%) ou Engenharia Química (5,0\%). Nenhum entrevistado diferenciou pigmento e corante quanto as suas naturezas orgânica e inorgânica, o que era esperado, pois é uma parte muito específica deste assunto. A maior parte dos entrevistados possuiu bastante dificuldade em diferenciar um material de origem orgânica de inorgânica. Substâncias orgânicas foram mencionadas como inorgânicas. O caramelo IV, cuja matéria prima é o carboidrato, e o azul de metileno, foram algumas dessas substâncias. Isso demonstra que estes conceitos (orgânico e inorgânico), não estão claros para estes alunos, e por isso a dificuldade evidente. Apesar disso, o pigmento de origem inorgânica mais citado pelos entrevistados foi o dióxido de titânio, e apenas uma pessoa respondeu minerais ou terras naturais.

A respeito da contribuição da biologia e química no estudo da arte, a faixa etária 51-61 anos não soube responder. Dois indivíduos da faixa etária 40-50 anos disseram não saber. Em relação as faixas etárias 18-28 anos e 29-39 anos, uma pessoa não soube responder. Além disso, alguns entrevistados que disseram que as duas ciências podem ser aplicadas na arte, porém, não justificaram suas respostas. Embora, maior parte dos entrevistados tenha demonstrado grande dificuldade em explicar de que maneira a biologia e química podem ser aplicadas na arte, estudantes da área de técnico em Química ou Controle Ambiental ou indivíduos que possuíam 18 a 28 anos elaboraram respostas muito interessantes. Algumas dessas respostas foram selecionadas:

A Biologia e Química podem ser aplicadas:

•Na detecção de falsificações e na restauração de obras.

-Na produção de tintas menos nocivas em toda a sua cadeia produtiva, desde a extração da matéria prima até o descarte de resíduos.

•Na preservação e conservação de obras antigas.

-Na durabilidade de cada tinta.

\section{Conclusão}

Foi possível utilizar uma tecnologia de informação e comunicação, o Google Forms, como uma ferramenta avaliativa. A avaliação diagnóstica serviu para verificar o grau do conhecimento prévio que os alunos possuíam a respeito do assunto a ser estudado e identificar os pontos em que tinham maior facilidade ou dificuldade. A partir desse ponto de partida, pretende-se aplicar aulas experimentais envolvendo os conceitos presentes no formulário.

A partir da pesquisa bibliográfica realizada foi possível avaliar quais as técnicas e matérias primas utilizadas para a produção de tintas e corantes utilizando materiais de baixo custo. Dessa forma, pretende-se desenvolver um projeto de cunho interdisciplinar, envolvendo as disciplinas de química, física e biologia em turmas de ensino médio.

Os entrevistados com formação técnica em Química ou Controle Ambiental e os que possuíam entre 18 e 28 anos demonstraram ter um entendimento mais claro sobre a aplicação da ciência na arte. Já, aqueles que possuíam entre 51 e 61 anos, apresentaram dificuldade em elaborar suas respostas. Apesar disso, cada aluno respondeu de forma mais adequada às perguntas mais relacionadas com sua área de formação. 
Os autores destacam que pretende-se utilizar as informações e conhecimentos adquiridos a partir da presente pesquisa para implementar metodologias ativas em sala de aula, como a extração de pigmentos e corantes naturais para pinturas. Essas atividades serão desenvolvidas de forma presencial, assim que possível, devido às condições sanitárias atuais e considerando os parâmetros de biossegurança exigidos nas Instituições de Ensino citadas.

\section{Referências}

Almeida, A. N., Santos, S. F., Sampaio, J. A., Luz, A. B., Ogasawara, T., \& Andrade, M. C. (2007). Síntese de Pigmentos Cerâmicos por Precipitação Química. Cerâmica, 53 (25), 57-61.

Alves, P. A. (2006). Técnicas para a análise de pigmentos. In: Pigmentos e corantes naturais entre as artes e as ciências, 2006, Évora, Portugal. Workshop Évora: Câmara Municipal de Évora, 38-45.

Augusto, T. G., Caldeira, A. M., Caluzi, J. J., \& Nardi, R. (2004). Interdisciplinaridade: concepções de professores da área ciências da natureza em formação em serviço. Ciência \& Educação, 10 (2), 277-289.

Ementas das disciplinas do Curso de Biologia (2020). Portal CEDERJ. https://www.cecierj.edu.br/wp-content/uploads/2019/09/Ementas-das-disciplinasCi\%C3\%Aancias-Biol\%C3\%B3gicas-UFRJ-UERJ-UENF.pdf.

Parâmetros Curriculares Nacionais: Apresentação dos temas transversais, ética (1997). Portal Ministério da Educação. http://portal.mec.gov.br/seb/arquivos/pdf/livro081.pdf.

Parâmetros Curriculares Nacionais: Diretrizes para uma pedagogia da qualidade (2000). Portal Ministério da Educação. http://portal.mec.gov.br/seb/arquivos/pdf/blegais.pdf.

Campos, D. D., \& Leão, M. F. (2018). Utilização do urucum pelos indígenas Terena do Mato Grosso e do Mato Grosso do Sul: divulgação de saberes tradicionais e científicos. Exatas Online, 9 (1), 12-30.

CENSO da Educação a Distância (2018-2019). Associação Brasileira de Educação a Distância. http://abed.org.br/arquivos/C ENSO_DIGITAL_EAD_2018_PORTUGUES.pdf.

Crizel, R. L. (2017). Prospeç̧ão de pigmentos produzidos por cochonilhas Ceroplastes spp. para aplicação em alimentos. 2017. (Dissertação de Mestrado em Ciência e Tecnologia de Alimentos, Universidade Federal de Pelotas, Pelotas, RS). http://guaiaca.ufpel.edu.br/handle/prefix/3260.

Cruz, A. J. (2006a). Os pigmentos naturais utilizados em pintura. In: Pigmentos e corantes naturais entre as artes e as ciências. Évora, Portugal. Workshop Évora: Câmara Municipal de Évora, 38-45.

Cruz, A. J. (2007b). Pigmentos e corantes das obras de arte em Portugal, no início do século XVII, segundo o tratado de pintura de Filipe Nunes. Conservar Património, 6, 39-51.

Dufossé, L., Galaup, P., Yaron, A., Blanc, P., Arad, S. H, Murthy, K. N. C., \& Ravishankar, G. A. (2005). Microorganims and microalgae as sources of pigments for food use: a scientific oddity or an industrial reality? Trends in Food Science \& Technology, 16, 389-406.

Gomes, H., Rosina, P., \& Oosterbeek, L. (2014). Natureza e processamento de pigmentos de pinturas rupestres. In: Dinis, P.A., Gomes, A., Rodrigues, S.M. (Ed). Proveniência de materiais geológicos: abordagens sobre o quaternário de Portugal. Coimbra. APEQ, 193-212.

Kraemer, M. É. P. (2005). Avaliação da aprendizagem como processo construtivo de um novo fazer. Revista da Avaliação da Educação Superior, 10(2), 137147.

Mello, V. M., \& Suarez, P. A. (2012). As formulações de Tintas Expressivas através da História. Revista Virtual Química, 4 (1), 2-12.

Mendonça, A. G. (2013). Avaliação diagnóstica inicial em turmas do PROEJA-FIC: contribuições para uma aprendizagem significativa. Revista Iluminart, 10, $81-92$.

Mugnaini, R., \& Strehl, L. (2008). Recuperação e impacto da produção científica na era Google: uma análise comparativa entre o Google acadêmico e a Web of Science. Encontros Bibli: Revista eletrônica de biblioteconomia e ciência da informação, 13 (1), 92-105. https://periodicos.ufsc.br/index.php/eb/article/view/1518-2924.2008v13nesp1p92.

Navegantes, R., Hogan, D. J., Tucci, C. E., \& Jr, A. P. (2000). Interdisciplinaridade em Ciências Ambientais. Signus Editora.

Pereira A. S., Shitsuka, D. M., Parreira, F. J., \& Shitsuka, R. (2018). Metodologia da pesquisa científica. UFSM Editora.

Santos, M. E., \& Santos, E. C. (2017). O Google acadêmico como mecanismo de auxílio na construção de trabalhos científicos e correlato ao letramento informacional. VIII Seminário de Saberes Arquivísticos, João Pessoa, 307-320.

Sivico, M. J., Gomes, R. da V., Ventura, L. A., \& Mendes, A. N. F. (2021). Reflecting on teaching practice in the school environment: A necessary singular dialogue from the perspective of the chemistry student in Basic Education. Research, Society and Development, 10 (6), 1-9. https://rsdjournal.org/index.php/rsd/article/view/15577.

Teixeira, O. A. (2004). Interdisciplinaridade: problemas e desafios. Revista Brasileira de Pós-Graduação, 1 (1), 57-69.

Tripp, D. (2005). Pesquisa-ação: uma introdução metodológica. Educação e Pesquisa, 31 (3), 443-466.

Volpe, A. L., \& Marques, R. N. (2016). Pigmentos inorgânicos no Egito Antigo: metodologia ativa para o Ensino interdisciplinar de química. In: V Congresso Pesquisa do ensino. (p.1-12). 